http://jmscr.igmpublication.org/home/ ISSN (e)-2347-176x ISSN (p) 2455-0450

crossref DOI: https://dx.doi.org/10.18535/jmscr/v8i1.27

Journal Of Medical Science And Clinical Research

\title{
Distribution of anaemia and leukemia in an urban cohort
}

\section{Authors \\ Bimla Banjare1, Aditi Das ${ }^{1 *}$, Amit Kumar Bhardwaj , Jalaj Gautam, Piyush Bhargava ${ }^{2}$}

${ }^{1}$ Department of Pathology, Pt. Jawaharlal Nehru Memorial Government Medical College, Raipur (C.G), India

${ }^{2}$ Department of Biochemistry, Pt. Jawaharlal Nehru Memorial Government Medical College, Raipur (C.G), India

*Corresponding Author

Dr Aditi Das

Assistant Professor, Department of Pathology, Pt. Jawaharlal Nehru Memorial Medical College, Raipur (C.G), India

Abstract
Background: It is important to screen the population for early detection of haematological diseases, so
as to avoid grievous consequences. This study was undertaken in a tertiary care centre to determine the
impact of such diseases, especially leukemias and anaemias in general population.
Subjects and Methods: This was a 6 months prospective study which was undertaken on 1764 patients
who on complete blood count (CBC) analysis presented with low haemoglobin or abnormal leukocyte
and platelet counts. The CBC, peripheral smear (PS) and bone marrow evaluation were done
subsequently.
Results: In our study, 54 patients were diagnosed with leukemia, among them $9 / 54$ had normal total
leukocyte count at presentation while $6 / 54$ patients had pancytopenia. Bone marrow aspiration was done
in 23 patients. Acute lymphoblastic leukemia (ALL) was found to be the most common leukemia in 0 -10
years age group; chronic myeloid leukemia (CML) was common in $31-40$ years age group while chronic
lymphocytic leukemia (CLL) was common in >50 years age group. Overall, unclassified leukemias
(n=28) were the most commonly reported leukemia. The most common anemia was microcytic
hypochromic anaemia. Male: female ratio in leukemia was found to be $1.84: 1$ Thrombocytopenia was
present in $37 \%$ of all leukemic patients.
Conclusion: The proper and thorough investigational approach is needed for early diagnosis of
anaemias and leukemias which in a true sense are potentially curable and often preventable entities. The
value of basic investigations such as CBC and PS evaluation cannot be underestimated and at times
becomes the most crucial to screen the population for the presence or absence of such deadly
haematological disorders.

\section{Introduction}

Haematological diseases affects millions, resulting in high morbidity and high mortality. ${ }^{[1]}$ Due to the high prevalence of anaemia and leukemia, it is absolutely necessary to diligently screen the entire population. According to a survey, 07 out of every 10 children aged 06-59 months are anaemic with
$3 \%$ being severely anaemic, $40 \%$ moderately and $26 \%$ mildly anaemic. As per a anaemia statistics report 2019, anaemia affects $24.8 \%$ of the world population (i.e. approximately 1.62 billion people) with the highest prevalence noted in preschoolage children $(47.4 \%, 95 \%$ CI: 45.7-49.1), and the lowest in men $\left(12.7 \%\right.$, 95\% CI: 8.6-16.9\%). ${ }^{[2-4]}$ 
ALL accounts for 60 to $85 \%$ of all childhood leukemia. Incidence of leukemia in Indian pediatric population was reported as $34 \%$, of which $25 \%$ was ALL. Acute lymphoblastic leukemia (ALL) is the single most common pediatric malignancy accounting for $1 / 4$ th of all childhood cancer and 3/4th of all newly diagnosed leukemia constituting approximately 3- 4 cases per 100,000 children under the age of 15 years. ${ }^{[5]}$ In India, more than 25,000 children are diagnosed with this cancer every year. AML accounts for approximately $20 \%$ of acute leukemia in children and $80 \%$ in adults and is the second most common leukemia in children. ${ }^{[6]}$ The highest rates of childhood acute myeloid leukemia (AML) occurs in Asia. Annual incidence of AML in India varies from 0.9 to 1.5 per 100,000 children. Hence, it is essential to investigate all the cases properly to timely arrest the progression of such fatal entities.[6] In the current study, complete blood count (CBC) and peripheral smear (PS) evaluation was done to detect anaemia/ leukemia and the associated thrombocytopenia/ thrombocytosis. The usual indications for bone marrow aspiration was to confirm the diagnosis, to determine the stage or progression of a disease, to monitor the response of the treatment and to investigate pancytopenias and pyrexias of unknown origin.

\section{Subjects and Method}

Study Design: This was a 6 months prospective study which was undertaken on 1764 patients. The approval of the study was obtained from the institutional ethical committee and written informed consent was obtained before attempting any bone marrow aspiration from the patients involved in the study.

Subjects: Inclusion criteria: The patients of all the age groups were included in this study who on $\mathrm{CBC}$ analysis presented with low haemoglobin or abnormal leukocyte and platelet counts. Exclusion criteria: seriously ill patients with various comorbidities.

Method: The blood collection for PS and CBC evaluation was done as a routine procedure at our department. $\mathrm{K}_{2}$ EDTA was the preferred anticoagulant.

Procedure: Prior to any bone marrow aspiration, the vitals of the patient were checked, and the local anesthesia was injected around the precleaned area (preferred site- the posterior iliac crest) where the biopsy needle was chosen to be inserted. A small incision was made, then a hollow needle was inserted through the bone and into the bone marrow. Using a syringe attached to the needle, a sample of the liquid portion of the bone marrow was withdrawn. Following which the aspirate was used to be spread over many slides for further staining and subsequent microscopic evaluation. The stain utilized for staining PS and bone marrow aspiration was Leishman stain. The special stains were also used as and when needed.

\section{Statistical Analysis}

The interpretation and analysis of the data was done by using Microsoft Excel and plotted in the spreadsheets. The quantitative data obtained were expressed as numbers and percentages in a tabular form.

\section{Results}

In our study, total 54 patients were diagnosed with leukemia among them 9/54 had normal total leukocyte count at presentation while 6/54 patients had pancytopenia. Bone marrow aspiration was done in 23 patients. ALL was found to be the most common leukemia in $0-10$ years age group; CML was common in 31-40 years age group while CLL was common in $>50$ years age group. [Table 1, Figure 1]. Overall, unclassified leukemias $(n=28)$ were the most commonly reported leukemia. The most common anemia was microcytic hypochromic anaemia. [Table 2, Figure 2] Male: female ratio in leukemia was found to be 1.84:1. [Table 3] Thrombocytopenia was present in $37 \%$ of all leukemic patients. [Table 4] 
Table 1: Distribution of Leukemia in various age-groups

\begin{tabular}{|l|c|c|c|c|c|c|}
\hline Age group & $\begin{array}{c}\text { Number of } \\
\text { patients } \\
(\mathrm{n}=54)\end{array}$ & $\begin{array}{c}\text { ALL } \\
(\mathrm{n}=12)\end{array}$ & $\begin{array}{c}\text { AML } \\
(\mathrm{n}=08)\end{array}$ & $\begin{array}{c}\text { CLL } \\
(\mathrm{n}=02)\end{array}$ & $\begin{array}{c}\text { CML } \\
(\mathrm{n}=04)\end{array}$ & $\begin{array}{c}\text { Unclassified } \\
\text { Leukemia } \\
(\mathrm{n}=28)\end{array}$ \\
\hline $0-10$ years & 07 & 1 & 3 & 0 & 0 & 3 \\
\hline $11-20$ years & 11 & 3 & 1 & 0 & 1 & 6 \\
\hline $21-30$ years & 14 & 3 & 1 & 0 & 1 & 9 \\
\hline $31-40$ years & 10 & 2 & 0 & 0 & 2 & 6 \\
\hline $41-50$ years & 06 & 2 & 2 & 0 & 0 & 2 \\
\hline$>50$ years & 06 & 1 & 1 & 2 & 0 & 2 \\
\hline
\end{tabular}

Figure 1: Age-wise distribution of leukemia

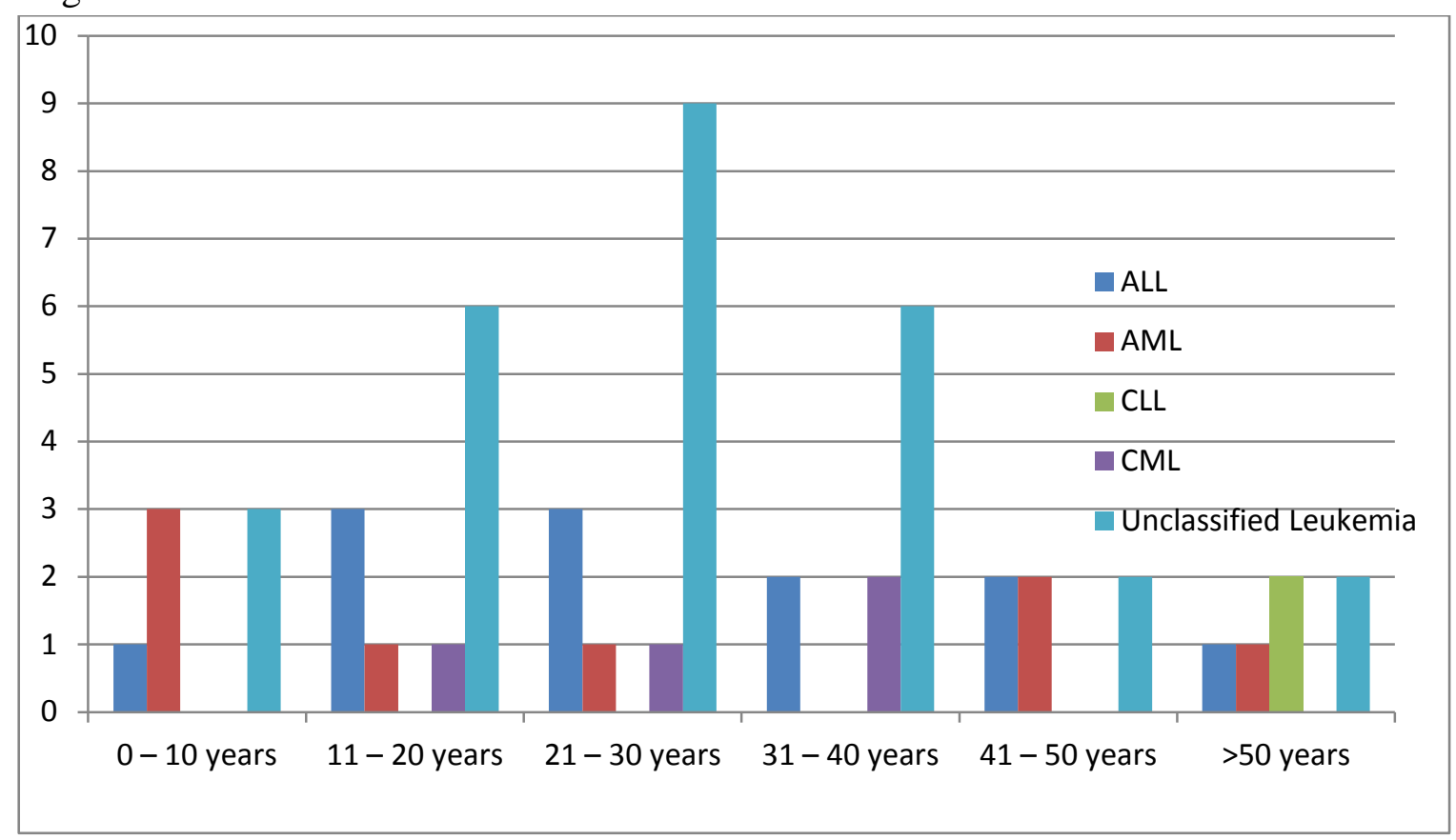

Table 2: Distribution of anaemias and leukemias among 1764 patients

\begin{tabular}{|c|c|c|}
\hline Disease & Classification & No. of cases \\
\hline \multirow{4}{*}{$\begin{array}{l}\text { Anaemias } \\
(\mathrm{n}=1710)\end{array}$} & Microcytic Hypochromic & 806 \\
\hline & Normocytic Normochromic & 620 \\
\hline & Macrocytic & 220 \\
\hline & Dimorphic & 64 \\
\hline \multirow{5}{*}{$\begin{array}{l}\text { Leukemias } \\
(\mathrm{n}=54)\end{array}$} & Acute Leukemia (Unclassified Leukemias) & 28 \\
\hline & ALL & 12 \\
\hline & CML & 08 \\
\hline & AML & 04 \\
\hline & CLL & 02 \\
\hline
\end{tabular}


Figure 2: Distribution of anaemia and leukemia in the study population

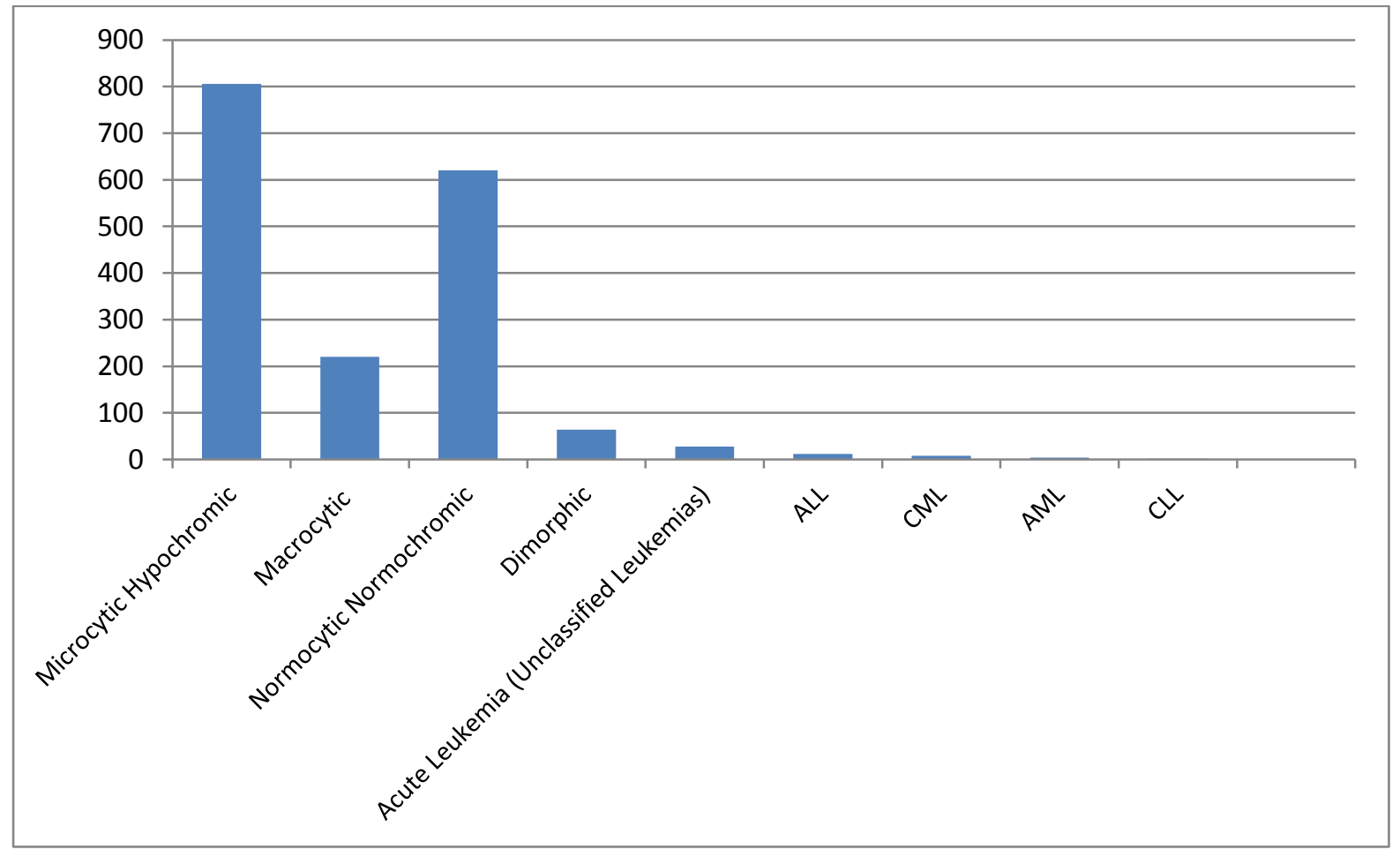

Table 3: Distribution of leukemia in males and females

\begin{tabular}{|l|c|c|}
\hline Leukemia & Male (n=35) & $\begin{array}{c}\text { Female } \\
(\mathbf{n = 1 9 )}\end{array}$ \\
\hline ALL & 6 & 6 \\
\hline AML & 3 & 1 \\
\hline CLL & 0 & 2 \\
\hline CML & 6 & 2 \\
\hline Unclassified & 20 & 8 \\
\hline
\end{tabular}

Table 4: Platelet count in leukemic patients

\begin{tabular}{|l|c|c|}
\hline & $\begin{array}{c}\text { Number of } \\
\text { cases }(\mathbf{n}=\mathbf{5 4})\end{array}$ & $\mathbf{\%}$ \\
\hline Thrombocytopenia & 20 & 37.03 \\
\hline Thrombocytosis & 02 & 03.7 \\
\hline Normal & 32 & 59.2 \\
\hline
\end{tabular}

In our study, a 9 year old girl presented to us with a 3 months history of fever on and off with generalized weakness. On CBC analysis, she had severe pancytopenia; her peripheral smear examination revealed few atypical cells with blast like morphology following which she was advised bone marrow aspiration. Finally the bone marrow findings revealed hypercellular marrow with the presence of more than $90 \%$ lymphoblasts favoring the diagnosis of acute leukemia, morphologically suggestive of ALL.

\section{Discussion}

As per various studies ${ }^{[1]}$, a vast majority of Indians of all ages are usually anaemic; the prevalence of anaemia ranged between $57.1 \%$ and $89.3 \%$ similar to that observed in our study, in which $96 \%$ were found to be anaemic. The high risk population who are prone for the development of anaemia includes females of reproductive age group, babies, especially if premature, children going through puberty, people following a strict vegetarian or vegan diet, people with cancer, stomach ulcers and some chronic diseases, people on fad diets and athletes. ${ }^{[3-4,9]}$ Microcytic hypochromic anemia was found to be the most common anemia similar to the studies done by various other researchers, especially iron deficiency anaemia ${ }^{[10-12]}$ It is important to detect such anaemias at the earliest to avoid grievous consequences, especially in very young children and pregnant women.

Among the patients suffering from leukemia, 9/54 had normal total leukocyte count at presentation while 6/54 patients had pancytopenia. ALL was found to be the most common leukemia in 0-10 years age group, ${ }^{[5]} \mathrm{CML}$ was common in $31-40$ years age group while CLL was common in $>50$ 
years age group similar to the previously established studies $^{[5]}$ which supports that ALL is more common in children and young adult, AML and CML occurs predominantly in middle age while CLL primarily affects elderly. According to various studies ${ }^{[5-7]}$, the commonest leukemia was CML followed by ALL, AML and CLL. The findings of our study varies from the above study due to different environmental, genetic, nutritional and economical factors. In a hierarchal approach, genetic changes have a precedence in the acute myeloid leukemia and immunology and genetic changes have a precedence in the acute lymphoblastic leukemia. In our study, many cases were unclassified leukemias where the blasts cell lineage could not be decided simply on the basis of morphological analysis. As per the current WHO classification of leukemia, genetic aberrations and immunology are now the major defining features in addition to morphology. However, in a limited resource settings, the cytogenetic analysis and other high end investigations are generally not feasible. In a study, of 156 cases, 90 were male and 66 were females with male: female ratio is $1.36: 1$ whereas in our study male: female ratio was found to be 1.84:1. Thrombocytopenia was present in $37 \%$ of all leukemic patients which was similar to the findings seen in other studies ${ }^{[5-7]}$ Radiation exposure, Benzene, aromatic hydrocarbons, drugs like alkylating agents and other chemotherapeutic agents and Human T cells leukemia lymphovirus I and II, are particularly notorious to cause leukemias. ${ }^{[11]}$

The morphological features of various anaemias have already been discussed in the established literatures. Morphologically, as per FAB classification of acute lymphoblastic leukemia (ALL), L1 morphology is characterized by the presence of uniform-sized blasts, L2 ALL with more blast cell variation and L3 blasts is characterized by the presence of more clumped nuclear chromatin, nucleoli, basophilic cytoplasm, and cytoplasmic vacuoles. As per WHO classification, AML are currently subclassified into many subtypes and cytogenetic analysis is must; however simply on the basis of morphology, the auer rods is still the best hint towards the diagnosis. Only on the basis of morphology, acute leukemia subclassification classification should not be particularly attempted. Immunophenotyping analysis and cytogenetic study is must for definite categorization,

\section{Conclusions}

This study highlights the value of proper and thorough investigational approach needed for early diagnosis of anaemias and leukemias which in a true sense are potentially curable and often preventable. The basic investigations should always be recommended and needs to be carried out for the screening purposes.

\section{References}

1. McLean E, Cogswell M, Egli I, Wojdyla D, De Benoist B. Worldwide prevalence of anaemia, WHO Vitamin and Mineral Nutrition Information System, 1993-2005. PublicHealth Nutrition. 2008; vol. 12, no. 4, pp. 444-454.

2. Gore FM, Bloem PJ, Patton GC, Ferguson J, Joseph V, Coffey C, Sawyer SM, Mathers CD 2011. Global burden of disease in young people aged 10-24 years: A systematic analysis. Lancet 377: 20932102

3. Assessing the iron status of populations: report of a joint World Health Organization/ Centers for Disease Control and Prevention technical consultation on the assessment of iron status at the population level, 2nd ed., Geneva, World Health Organization, 2007.

4. Nutritional anaemias. Report of a WHO scientific group. Geneva, World Health Organization, 1968. (WHO Technical Report Series, No. 405).

5. Arthur DC, Bloomfield CD, Lindquist LL et al. Translocation $4 ; 11$ in acute lymphoblastic leukemia: clinical 
characteristics and prognostic

significance. Blood 1982;59:96-99.

6. Barnard DR, Kalousek DK, Wiersma SR et al. Morphologic, immunologic, and cytogenetic classification of acute myeloid leukemia and myelodysplastic syndrome in childhood: a report from the Children's Cancer Group. Leukemia 1996;10:5-12.

7. Melo JV, Barnes DJ. Chronic myeloid leukaemia as a model of disease evolution in human cancer. Nat Rev Cancer. 2007;7(6):441-453

8. Preventing and controlling anaemia through primary health care: a guide for health administrators and programme managers. Geneva, World Health Organization, 1989

9. The management of nutrition in major emergencies. Geneva, World Health Organization, 2000. http://whqlibdoc.who.int/publications/200 0/9241545208.pdf 5. FAO, WHO. World Declaration and Plan of Action for Nutrition. International Conference on Nutrition. Rome, Food and Agriculture Organization of the United Nations, December 1992.

10. Miller JL. Iron deficiency anemia: a common and curable disease. Cold Spring Harb Perspect Med. 2013;3(7):a011866. Published $2013 \quad$ Jul 1. doi:10.1101/cshperspect.a011866

11. WHO, UNICEF, UNU. Iron deficiency anaemia: assessment, prevention and control, a guide for programme managers. Geneva, World Health Organization, 2001.

12. Cook JD 2005. Diagnosis and management of iron-deficiency anaemia. Best Pract Res Clin Haematol 18: 319332

13. Buckley JD. The aetiology of cancer in the very young. Br J Cancer Suppl 1992; XVIII:S8-S12. 